\title{
Challenges of Restoration and Storage of a weak Historical Textiles in Uncontrolled Museum Con- ditions; Practical Applications
}

ISSN: 2578-0271

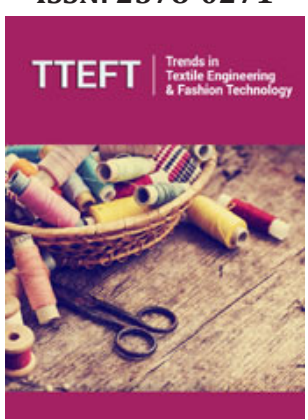

*Corresponding author: Harby E Ahmed, Faculty of Archaeology, Egypt

Submission: 眥 March 09, 2019

Published: 㱕May 30, 2019

Volume 5 - Issue 2

How to cite this article: Amr s, Mohamed h, Harby E A. Challenges of Restoration and Storage of a weak Historical Textiles in Uncontrolled Museum Conditions; Practical Applications. Advancements Bioequiv Availab.5(2). TTEFT.000607.2019.

DOI: 10.31031/TTEFT.2019.05.000607.

Copyright@ Harby E Ahmed, This article is distributed under the terms of the Creative Commons Attribution 4.0 International License, which permits unrestricted use and redistribution provided that the original author and source are credited.

\author{
Amr salah ${ }^{1}$, Mohamed hamed ${ }^{1}$ and Harby E Ahmed ${ }^{2 *}$ \\ ${ }^{1}$ Ministry of Antiquities, Egypt \\ ${ }^{2}$ Faculty of Archaeology, Egypt
}

\begin{abstract}
Historical textiles in uncontrolled storage conditions are presented to many aspects of damages. The historical object under registration number 58Kom Oshim museum, Fayoum. The object in a state of weakness, different type of dirt, stain, missing parts, unconnected yarns. A close examination was done in order to identify the type of fiber, dust, and other damage aspects. Moisturizing processes by using distilled water to eliminate severe dehydration in the historical object. Mechanical cleaning process by using different types of soft brushes to get rid of the dust on the object. Wet cleaning process was done to remove the resistance stain and dirt. Then the drying processes of the object after washing was done. Supporting and strengthening the weak parts was carried out. Rolling storage method was carried out as a temporary method.
\end{abstract}

Keyword: Textile; Conservation; Examination; Cleaning; Storage; SEM

\section{Introduction}

The Egyptian Civilization period provided a rich treasure of different types of textiles. Some of these textiles especially in uncontrolled Museums storage are exposed to many challenges such as oscillate Relative Humidity (RH), changing temperature, effect of light, effect of air pollution, nonstandard storage and display methods, old poor restoration and old type of adhesives. All these factors cause damage and decay in both fibers and dyes which results in weakness in fibers and dye, hardness in fibers, separate parts, loss parts, stain and dust [1-8]. For effective restoration planning of the historical textiles, it is necessary to carry out a diagnosis of the materials that constitute the object. Many studies have focused on investigating the technology and types of materials for historical textiles [9-11]. The article aims to present the strategies for the conservation of historical textiles in uncontrolled museum conditions. It shows new methods in the conservation of historic textiles, at least in Egypt.

\section{The object}

The historical object is registered with a number 58 in the storeroom of the Kom Oshim Museum, Fayoum. It is written in the registration book of the museum that the historical object is a dress embroidered; the main color is red color. The object was found with other historical objects with one of the people in case No. 368 of 1954. Possibly the object regional the area of Akhmeem, Sohag. Dimension of the object is $165 \mathrm{~cm}$ height of $110 \mathrm{~cm}$ width. The historical object colored by different type of color such as red, yellow, and blue color. One can see insect damage and insect bodies on the historical object. The object is severe drought and contain different type of stain and dirt. In addition, the object contains separate and missing parts as shown in Figure 1.

\section{Documentation of the object}

Visual examination: The first step in documentation of the historical object is a visual examination. It is a very important step in conservation process. One can see by eyes some type of deteriorations without need SEM or other examination methods. It is appearing the weak condition of the object, lost parts, dirt and stain in different parts of the object as shown in Figure 2; [12]. 


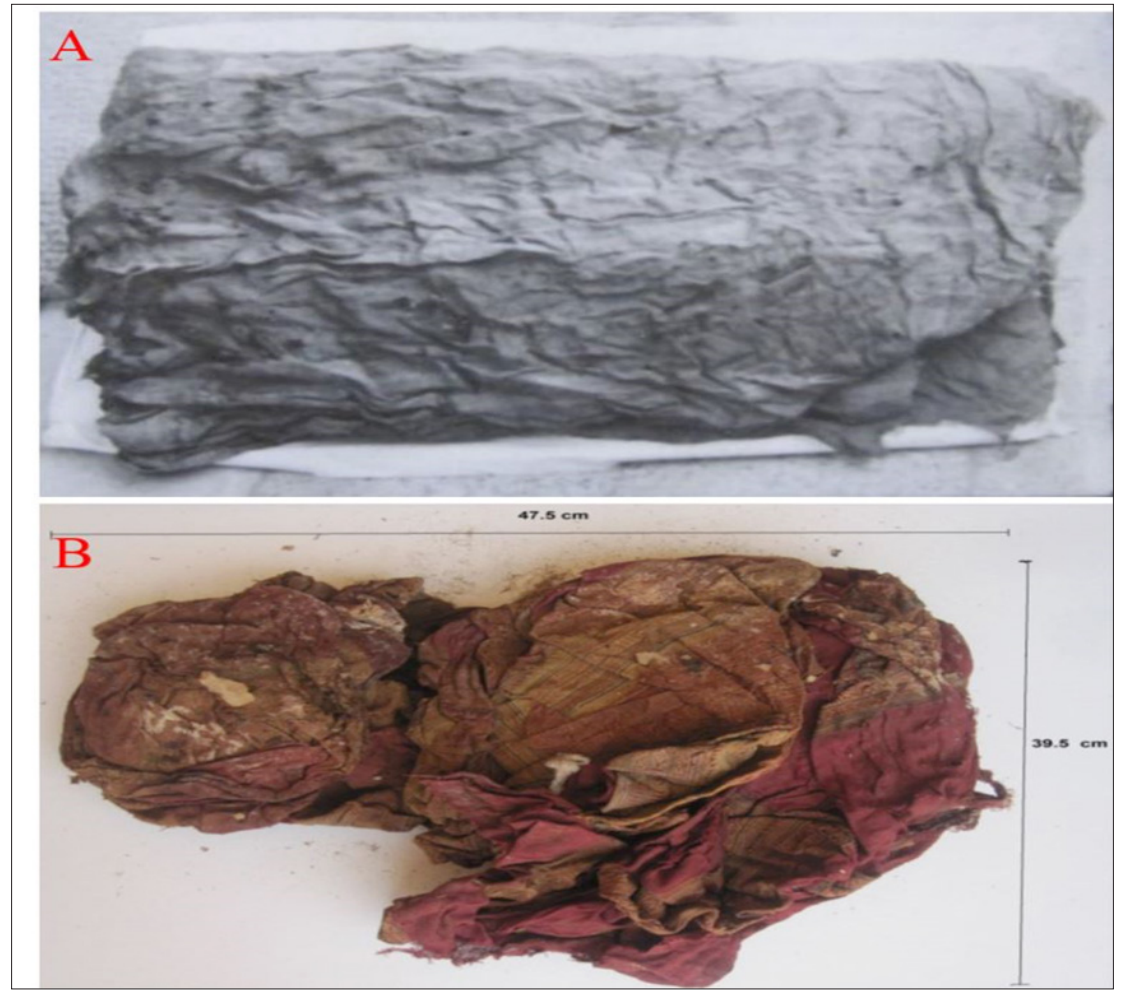

Figure 1: (A) The first photo of the object was taken at 1954. (B) While the other photo for the object at 2018 that show the deterioration aspects.

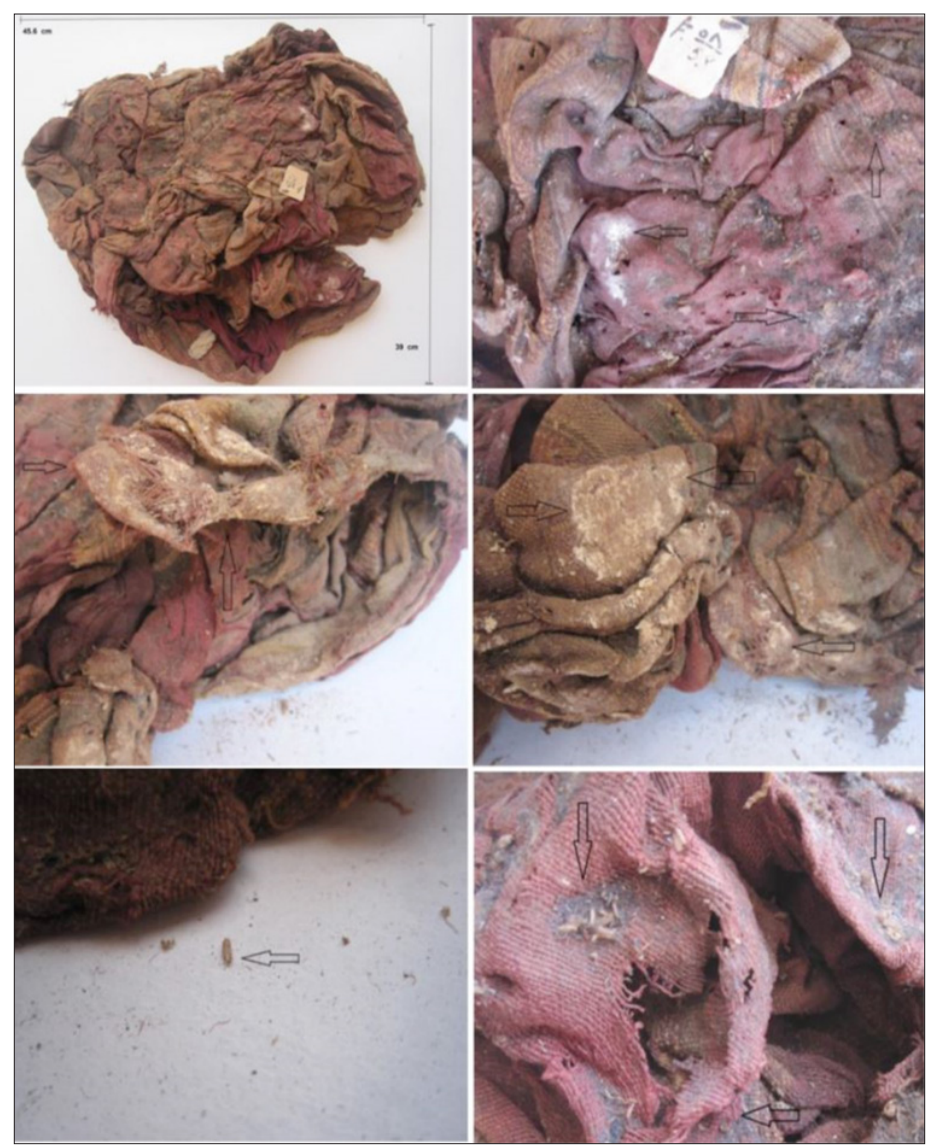

Figure 2: The deterioration aspects such as insect damage, insect bodies, separated parts, dirt, and stain on the surface of the object. 
USB microscope: Conservator need clear images with more details for documentation process. Therefore, the USB microscope is a suitable tool used to give clear images for the objects as shown in Figure 2,3; [13].

\section{Morphological examination}

The morphology of the surface of the fabrics was investigated using a HITACHI-SU-1500 Scanning Electron Microscope (SEM). Small samples taken from the object from different parts and inves- tigated under SEM, to show the quality of the fibers as well as the damage aspects on these fibers. SEM Photos of examined Historical object are illustrated in Figure 4 showing the Linen fibers that were identified from different parts of the object. The fibers are extremely roughened, damaged, broken with transverse cracking and longitudinal splitting characterized by small scratches, small slits and holes [14-16]. Furthermore, one can see the dust, dirt and adhesive that covered the fiber as shown in Figure 4.
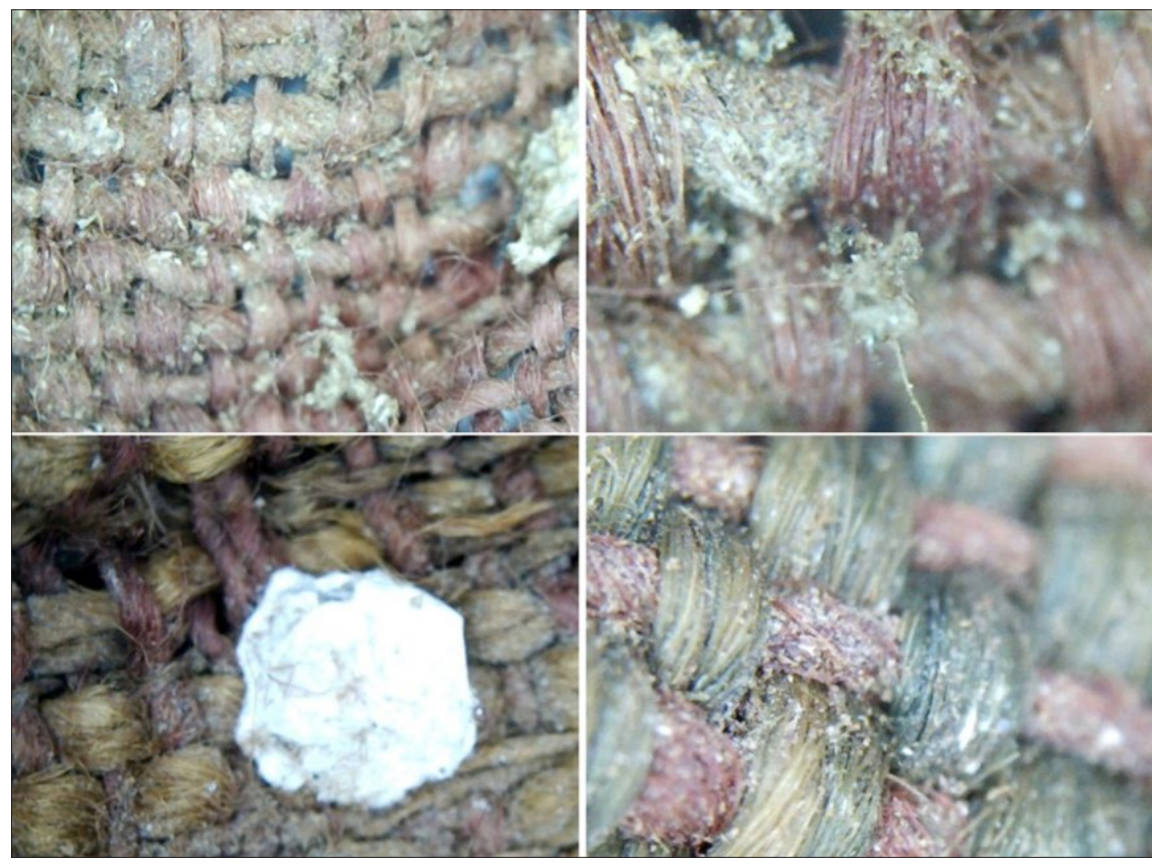

Figure 3: The USB microscope images of the historical object. One can see, the dirt, stain on the surface of the object.
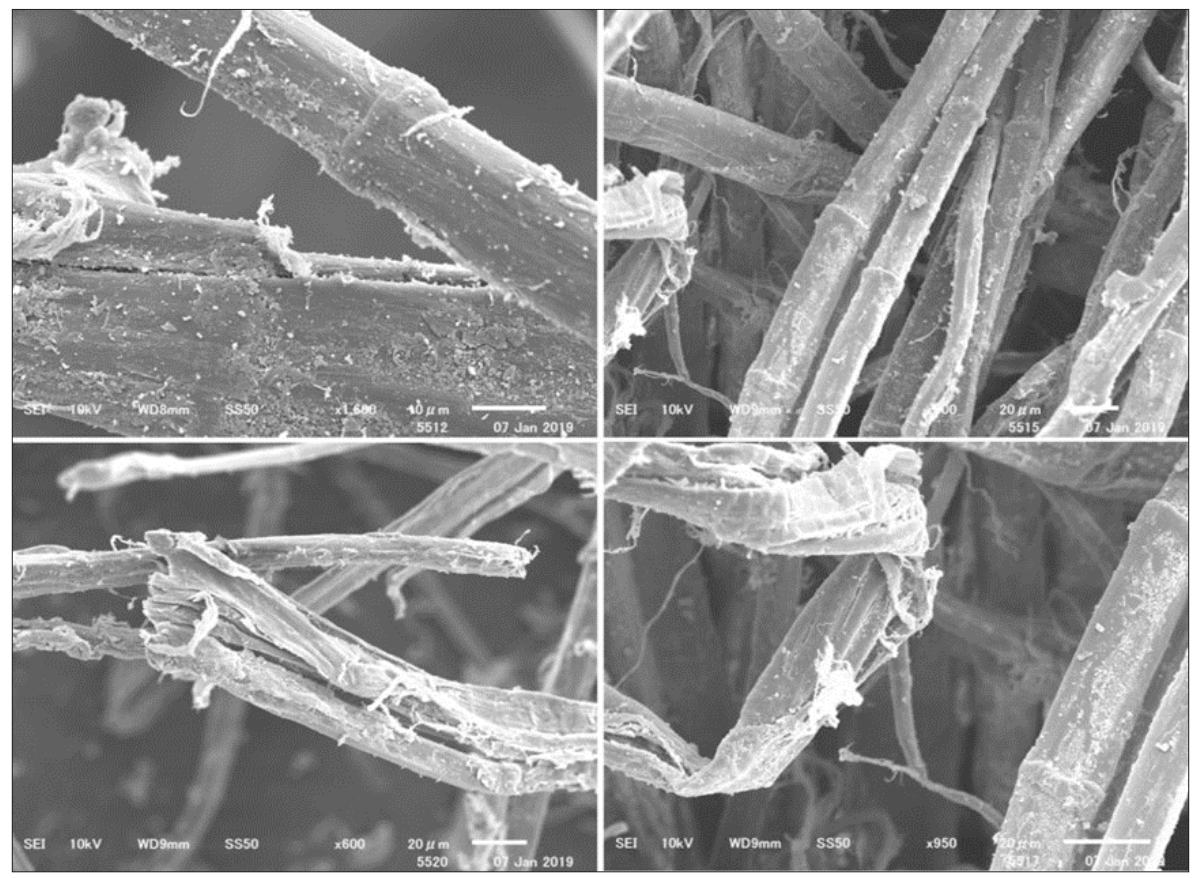

Figure 4: The SEM images of the historical object that show more details of the fiber's deterioration. It is appearing for the reader the type and quality of the fibers as well as the damage aspects on these fibers. 


\section{Mechanical cleaning}

The aim of conservation cleaning is to remove harmful soils, which may be disfiguring or causing physical or chemical damage to a textile. Selection of the appropriate cleaning method depends on the nature of the soil present, and on the materials, structure, and condition of the textile. Thorough testing should always be carried out first to determine the response of the textile to cleaning agents and to identify the most suitable method. Various types of fine brushes are used to remove free dust and dirt from the upper layers of the fabric. Surface dust was removed by using a vacuum cleaner as shown in Figure 5; $[17,18]$.

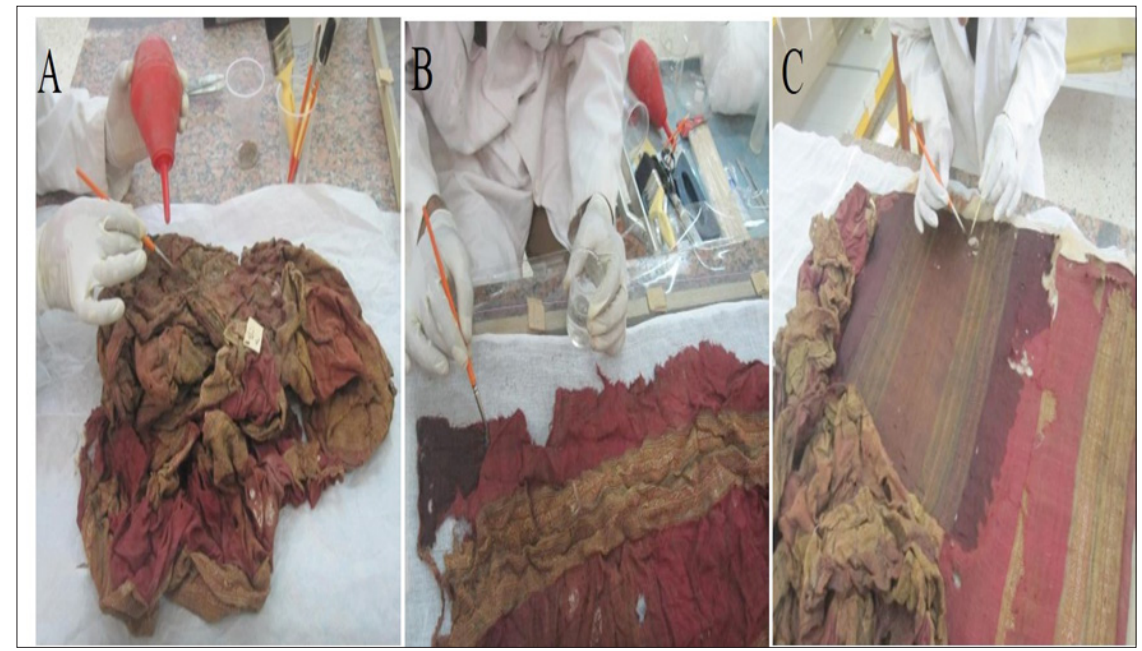

Figure 5: The mechanical cleaning of the historical object by using brushes (A). Hydration of the dried object by using distilled water (B and $\mathrm{C}$ ).

\section{Testing the stability of dyes}

Testing the stability of dyes for the washing solution is a very important step before wet cleaning process. This is step was done by using washing solution in small sparse parts of the historical object parts. It was found that all the dyes were stable and did not bleed with the wet cleaning solution [19].

\section{Wetting process}

The historical textile object suffers from severe dryness due to uncontrolled storage condition. At this stage, the dehydration was removed by using distilled water with soft brushes. The historical object regained some strength and flexibility. It is ready to carry out the other restoration process such as the wet cleaning, fixing and storage process as shown in Figure 5; [20].

\section{Wet cleaning}

A temporary wash bath was built by using four wooden tires and, lining the bath by polyethylene. This cleaning procedure used water with other detergent agents, to assist the cleaning process. The ratio was one-part detergent Synperonic N to 100 parts of distilled water. The water was agitated to allow it to penetrate between the fibers to release the dirt particles, for $15 \mathrm{mins}$. The bath temperature was $30 \mathrm{C}$. Then a second cleaning bath with distilled water only was applied for 10 mins again with water agitation, and then a third bath with distilled water only, for 10 mins as shown in Figure 6. The wet cleaning reduced the soiling, relaxed the fibers, removed the creasing and brightened the colors [21,22].

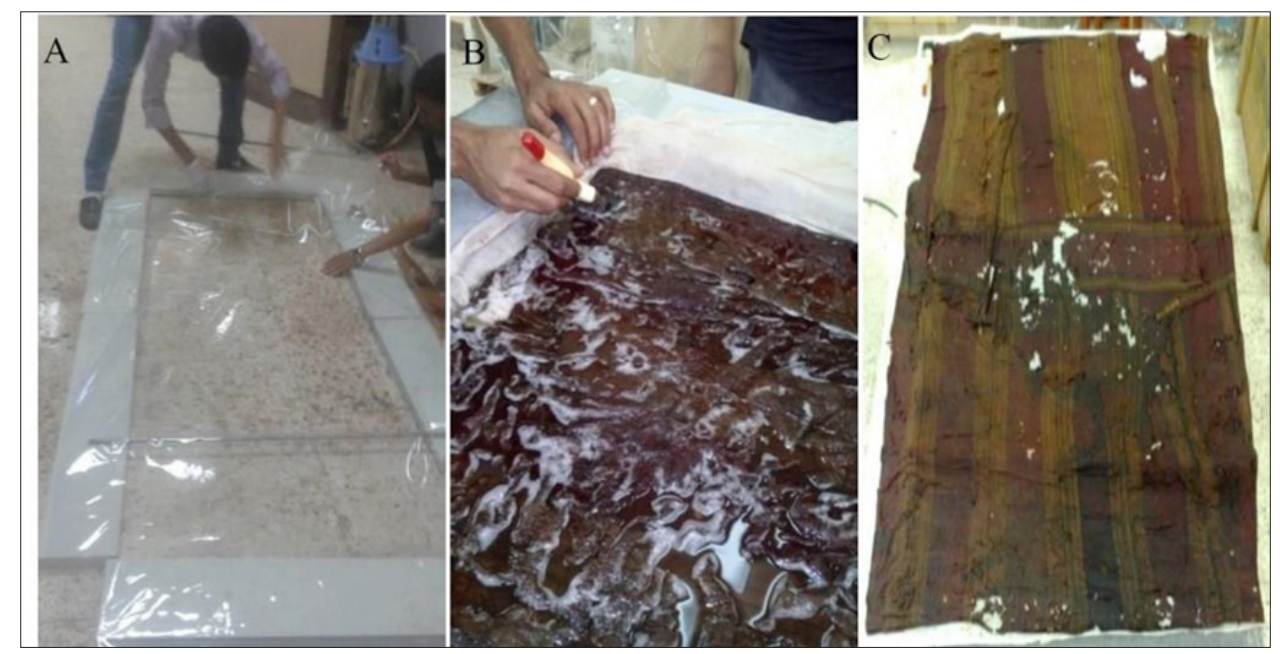

Figure 6: The temporary wash bath (A). Wet cleaning process by using water and detergent (B). Drying process of the object (C). 


\section{The drying process}

In order to dry and remove the residue water after wet cleaning from the object without distortions, a Japanese tissue sandwich using different tissues usugami or gampi was used and applied crossgrain or parallel-grain to the textile with varying amounts of moisture and pressure. Consequently, the object was left uncovered to complete drying at ambient conditions as shown in Figure 6; [23].

\section{The final support processes}

After completion of the object treatment, tacking stitches were used with a very fine needle and fine silk thread to fix it into the object. In the beginning of the final stage, the edges of the object all around were attached by sewing with a small stitch technique (blanket stitch) and afterwards the edges of the missing and vulnerable parts were attached by small stitches. Similarly, sized stitches were used to attach the body of the object. After completing the cleaning process and fixing the object, it could be storage in a suitable manner according to the museum requirements. The completion of the missing parts was not carried out at this stage. One can see the object in final stage in Figure 7,8; $[24,25]$.

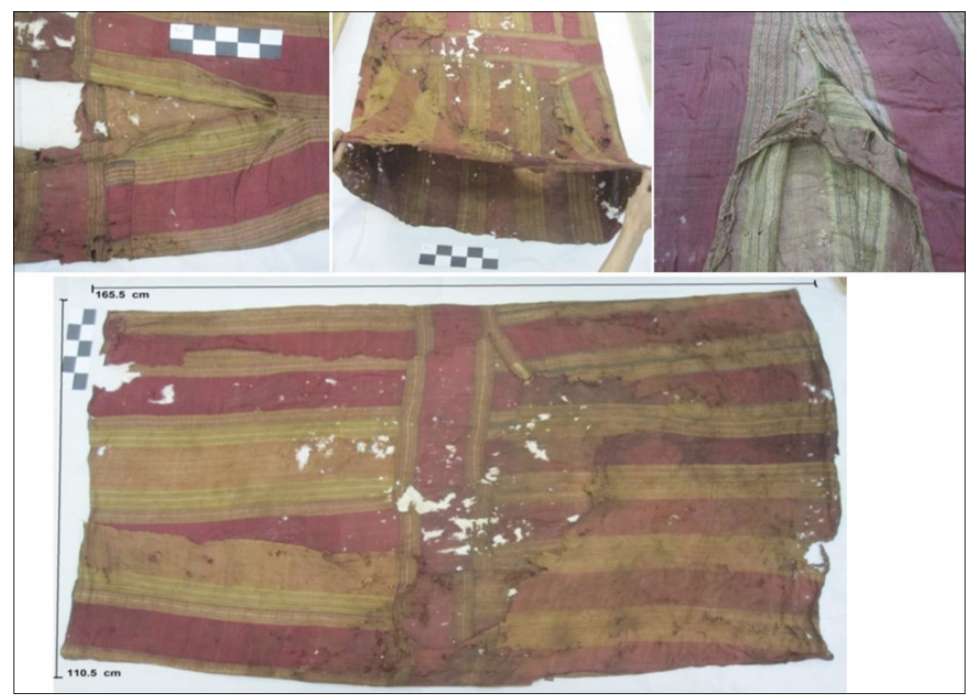

Figure 7: Details of the historical object after supporting the week parts.

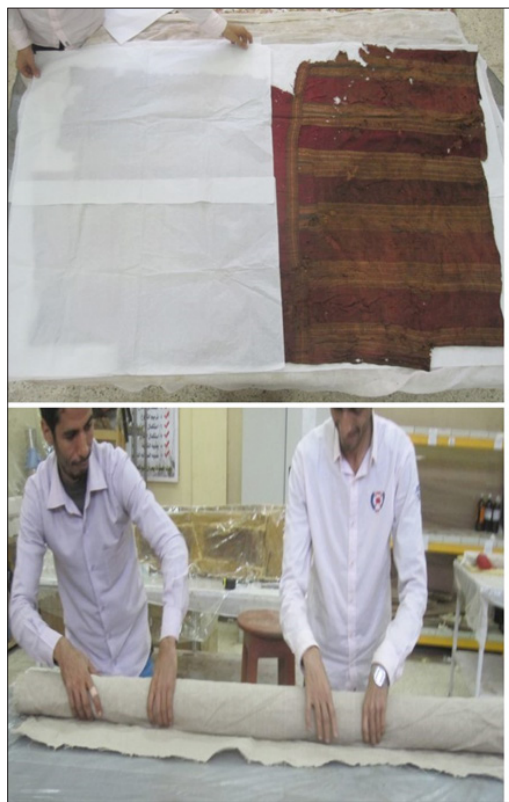

Figure 8: Storage process of the historical object.

\section{The temporary storage processes}

The overall goal of any storage method should be to protect the object from the agents of deterioration aspects. The method chosen for storing any textile should be based on the textile's condition and size, and all materials that come in direct contact with the object.

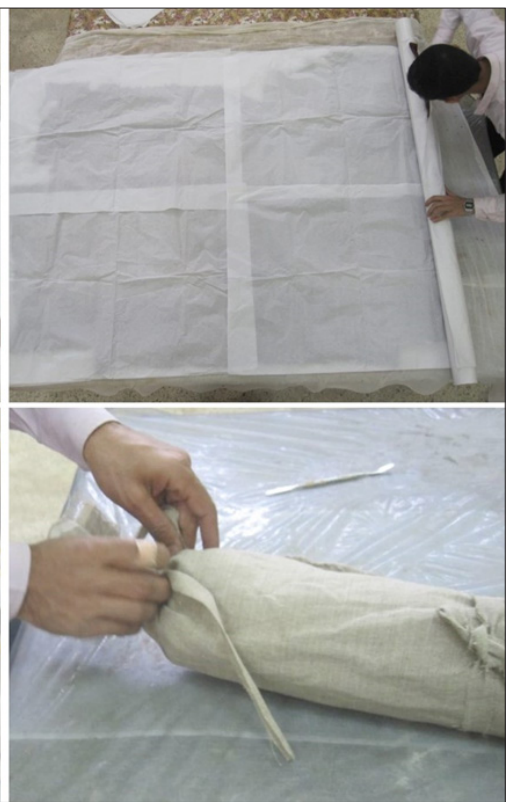

The storage process of this object is a temporary stage for a short term, the object will display in the museum. Just the storage done in order to keep the historical object during the short-term period. So, rolling used with the historical object as a efficient storage technique. Cardboard tube with a suitable diameters and lengths used 
for rolled storage. Cardboard tube was covered and warped by using washed Linen fabric. Historical textiles object was gently rolled on the cardboard tube. Acid free tissue paper is rolled between the layers of the object. Washed and prepared linen fabric used as a cover in cases over the object after rolled. Wide linen fabric strips used as knots or tying to secure items that may come unrolled easily. After rolling, the object stored in areas where they are protected from sunlight and dust but still well ventilated [26,27].

\section{Conclusion}

Historical textiles suffer from the influence of the uncontrolled storage environment in museums. Therefore, the historical textiles need periodic conservation. The investigations are very important in the identification of historical textile materials and damage aspects. Mechanical cleaning of the important stages in the cleaning and disposal of dust. The wet cleaning reduced the soiling, relaxed the fibers, removed the creasing and brightened the colors. The aim of storage process to protect the historical textiles from the agents of deterioration aspects.

\section{Acknowledgment}

Some investigation of this work was done at the Saga University, Japan during JSPS Invitational Fellowship for Research, with Dr. Mie Ishii as a Host Professor. The author is deeply grateful to Saga University, Japan Society for Promotion of Science (JSPS), and Dr. Mie Ishii.

\section{References}

1. Tímár B, Eastop D (1998) Chemical principles of textile conservation. Butterworth-Heinemann, London.

2. Landi S (1998) The textile conservator's manual. $2^{\text {nd }}$ Edition, Butterworth-Heinemann, London.

3. Ahmed H (2012) First aid of rare ptolemaic textile in Tuna el-Gabel Excavation Egypt. e-Conservation magazine 23: 78-89.

4. Ahmed H (2013) Identification and conservation of a rare islamic textile decorated with metallic yarns. Egyptian Journal of Archaeological and Restoration Studies 3: 109 -118.

5. Ishii M (2005) Yellow dyes in Japanese kimono. Scientific Analysis of Ancient and Historic Textiles, Japan.

6. Ishii M, Moriyama T, Toda M, Kohmoto K, Saito M (2008) Color degradation of textiles with natural dyes and of blue scale standards exposed to white led lamps. Journal of Light \& Visual Environment 32(4): 370-378.

7. Brooks M, Eastop D (2011) Changing views of textile conservation. Getty Publications, USA.

8. Ahmed H, Darwish S (2012) Effect of museum conditions on historical dyed silk fabric with madder dye. Journal of Polymers and the Environment 20(2): 596-606.

9. Lister A (1996) Guidelines for the conservation of texties english heritage. Conservation and Technology Branch, London.

10. Ahmed H, Reda S, Yehia D, Ziddan Z (2016) Preventive conservation of historic textile from the ultraviolet degradation due to light exposure in egyptian museum. International Journal of Materials Science and Applications 5(6-2): 10-14.

11. Ahmed H, Gremos S, Kolisis F (2010) Enzymatic removal of the oily dirt from a coptic tunic using the enzyme lipase. Journal of Textile and Apparel Technology and Management 6: 1-17.

12. Ahmed H (2014) A new approach to the conservation of metallic embroidery threads in historic textile objects from private collections. International Journal of Conservation science 5(1): 21-34.

13. Ahmed H (2011) Strategy for preservation of ptolemaic wrapped mummy's linen in tuna el-gebel excavation, Egypt, a case study. International Journal of Conservation Science 2: 155-164.

14. Batcheller C (2004) Optical and scanning electron microscopy techniques for the determination of hair fibres from Romano-Egyptian textiles in Scientific analysis of ancient and historic textiles: informing preservation, display and interpretation: postprints, first annual conference, Archetype Publications, England, pp. 13-15.

15. Nicola G (1993) The examination and conservation of tow Indian textile. The Conservator 17: 102-111.

16. Ahmed H, Nassef O (2013) From Ptolemaic to modern inked linen via laser induced breakdown spectroscopy (LIBS). Analytical Methods 5: 3114-3121.

17. Amin E (2018) Conservation of a gauze textile from the tulunid period in egyptian textile museum CAIRO. International Journal of Conservation Science 9: 13-24.

18. Fiette A (1997) Tapestry restoration: an historical and technical survey. The Conservator 21: 28-36.

19. Quye A, Lennard F (2015) Materialising conservation science research for historical textiles. In: $1^{\text {st }}$ International conference on science and engineering in arts heritage and archaeology (SEAHA), London, UK.

20. Lennard F, Hayward M (2006) Tapestry conservation: principles and practice. Butterworth-Heinemann, London.

21. Greene S (1995) The cleaning and mounting of a large wool tapestry. Studies in Conservation 2:1-16.

22. Mason J (2016) Ultrasonic cleaning: An historical perspective. Ultrasonics Sonochemistry 29: 519-523.

23. Marincas O, Grigoriu A (2003) Conservation of post-byzantine textiles. Improvement of their preservation conditions and accessibility to citizens-the first results of a local Romanian project, in Cultural heritage research: a Pan-European challenge, Proceedings of the 5th EC conference, May 16-18, 2002, European Communities ICSC.

24. Pow C (1970) The conservation of tapestries for museum display. Studies in Conservation 15(2): 134-153.

25. Ahmed H, Ziddan Y (2011) A new approach for conservation treatment of a silk textile in Islamic art museum. Cairo Journal of Cultural Heritage 12(4): 412-419.

26. Glover J (1992) Conservation and storage: textiles. In: Thompson J (eds.), Manual of curatorship: A guide to museum practice Taylor \& Francis Group, London and New York, USA, pp. 302-339.

27. Ahmed H, Yahia D, Zidan Y (2018) Restoration and storage process for a rare historical textile in faculty of applied arts museum, helwan university. Egyptian Journal of Archaeological and Restoration Studies 8: $35-43$. 